\title{
The role of strategic innovation for sustainability of businesses during the covid-19 pandemic
}

\author{
Abdallah Abusalma ${ }^{a^{*}}$

\begin{tabular}{l}
\hline C H R O N I C L E \\
\hline Article history: \\
Received: December 20, 2020 \\
Received in revised format: \\
January 202021 \\
Accepted: March 22, 2021 \\
Available online: \\
March 22, 2021 \\
\hline Keywords: \\
Strategic Innovation \\
Business Sustainability \\
The Corona Pandemic \\
Adopting an Innovation Creation \\
Strategy \\
Adopting a Research and Devel- \\
opment Strategy
\end{tabular}

${ }^{a}$ Associate Professor - College of Business Administration, Lecturer - Al Ain University, Abu Dhabi, United Arab Emirates

\section{A B S T R A C T}

This study aimed to know the role of strategic creativity in the sustainability of business in the Jordanian tourism sector in the shadow of the Corona pandemic, in addition to knowing the impact of its growth and what is the level of strategic creativity in the Jordanian tourism sector. The study population may consist of all employees of tourism companies in Jordan with all their services, and a questionnaire was created in order to achieve the aim of the study. The study used the analytical, descriptive, quantitative approach, whereby a random sample (319) respondents were distributed. After analyzing the study, the results showed that the level of strategic creativity in the Jordanian tourism sector is high, and that strategic innovation has an impact on the sustainability of businesses in that sector. The study recommended the necessity of supporting the Research and Development Department as a strategy for tourism companies to get out of the Corona pandemic.

(C) 2021 by the authors; licensee Growing Science, Canada

\section{Introduction}

Any Organization is trying to sustain their business in order to keep up with the rapid developments heading towards globalization. And in an effort to invest its practices in improving its competitive advantage and distinction between their competitors during and after Covid-19 Pandemic, that stormed the world and changed the leaders' attitudes and the way they communicate with their followers, and this can be achieved for them through increased innovation from a strategic perspective. Despite the high capacity of strategic innovation in dealing with everything new and creating distinctive ideas, it is not easy to produce innovative strategic thinking, because it consists in creating strategies for growth, or new classes of products, services, or business models that generate a new value for customers and the organization (Purba, 2015). So, the importance of strategic innovation opens the door to innovative opportunities and areas for the development of the organization, also, creates a competitive environment for it capable of facing any entity in the market (Zarrabi et al., 2013). In addition, the strategic innovation is characterized by the disciplined implementation that helps to develop and design technical products and services through prototypes and tests, as well as building effective communication, and developing new ideas successfully (Kim, 2014). Organizations can improve their innovation capabilities through innovative strategies that can benefit from the organization's strengths and weaknesses, that also helps to identify and analyze innovation trends and global best practices. This is necessary to create an environment conducive to comprehensive and sustainable economic growth. It also provides an innovative strategy derived from the Sustainable Development Report (Schroeder, 2013). The problem of this paper is, that before the Corona pandemic, tourism income for Jordan reached \$ 5 billion for the year 2019, accounting for 13\% of GDP, and a sharp decline in Jordanian tourism is expected, the same as in most countries. These countries, which reached 70 million visitors, as in France, during the Corona pandemic, became completely devoid of tourists and exposed their economy to a severe blow, even though they are among the major industrialized countries. The tourism sector is one of the sectors most

\footnotetext{
* Corresponding author.

E-mail address: abdullah.abusalma@aau.ac.ae (A. Abusalma) 
affected, and according to the World Tourism Organization, global tourism is expected to decline by $40 \%$, causing losses of up to $\$ 500$ billion, at risk of 52 million jobs (Al-Khudairi, 2020).

The reason for this is the problem of the study to find new solutions and strategies suitable for the tourism sector, and from the problem the research questions are formulated according to the following:

- What is the level of implementation of strategic innovation and sustainability in the Jordanian tourism sector?

- What is the relationship between strategic innovation and sustainability in the Jordanian tourism sector?

- What is the impact of strategic innovation on sustainability in the Jordanian tourism sector?

\subsection{Strategic Innovation}

The innovation process from a strategic perspective has made operations move forward despite the diversity of financial or capacity-based obstacles (Meijer, 2015). Innovation can take many forms, such as presenting an existing idea and implementing it in new ways, because it encourages research and discovery. The development of traditional experiences, the adoption of new organizational forms (Perez et al., 2017), and innovation leads to growth in the competitiveness of commercial entities operating in the market (Skowron \& Sukiennic, 2015). Strategic innovation increases the flexibility of business, and it focuses on the most important elements in making the strategy more creative, and is linked to a solid relationship with goals and decision-making within the organization, as well as the practice of creative thinking and flexible implementation with the application of new technologies (Šebestová, 2013). The concepts that are related to strategic innovation refer to the ability to create a business idea and revitalize the concept of the organization by changing the competencies of the organization's market and its business system, and it has been defined as creating growth strategies, services, new product categories, and business models that generate new value for the organization, customers and consumers. (Zarrabi et al., 2013). Also, strategic innovation was known to direct the company to engage in engagement, support new ideas, and urge experimentation in operations innovation, which leads to the presence of new products, services, or technological processes (Shams et al., 2018). Strategic innovation also plays a major role in the organization, as strategy not only influences and directs the behavior of routine business operations, but also provides mainly for long-term success (Kasemsap, 2017).

The direct damage to the tourism sector as a result of the Corona pandemic has made it among the sectors most affected in Jordan and the world. And that the tourism sector is looking for solutions and ways to save the sector in addition to developing plans and strategies to restore life to it. The head of the Tourism Committee issued by the Jordanian Tourism and Travel Agents Association stressed that "the tourism sector is the first to be affected and the last to recover," and insisted on the necessity of saving the tourism and travel offices that were damaged in all their facilities.

\subsubsection{Adopting an Innovation Creation Strategy}

The success of global and local companies stands behind several reasons, on top of which are innovation and innovation, quality in services and products, and continuous improvement to maintain their survival and ability to compete. Innovation and innovation are considered an important and major factor, but decisive in the competition for companies and their ability to continue in the market, evidenced by the survival of creative companies such as Microsoft, Toyota, General Electric, Sony, Samsung, Nokia and other international companies that have renewed their products, technologies and business methods (Ezzi \& Jarboui, 2016). Innovation is defined as introducing something new or using new methods, ideas, or technologies, and it is also concerned with new and useful ideas related to solving specific problems such as the Corona pandemic and its economic crisis, or collecting and reconstructing known patterns of knowledge into unique forms (Kalay and Gary, 2015). It means transforming creative and development ideas into practical application, such as applying administrative and technical methods and techniques, programs and products.

Some of studies indicate that innovation at the level of organizations has two aspects: 1-Technical innovation: it relates to the product, whether goods or services, and it relates to production technology, that is, to the basic activities of the organization that result in goods or services (Al-Aktash, 2019). 2- Administrative innovation: It is directly related to the organizational structure and the administrative process in the organization, and indirectly to the basic activities of the organization (Schroeder, 2013).

\subsubsection{Adopting a Research and Development Strategy}

There is no doubt that research and development is one of the basic strategies that receive great attention from the officials of major companies in various parts of the world, due to their profound impact on creative processes and business sustainability. Some entrepreneurs may be afraid of entering into the risk of spending on research and development within the company, it is growing and accelerating in companies in the United States and Japan, and it has also witnessed a great increase in China, India and some countries in South and East Asia. So, whenever there is research and development within companies, there is a real and diversified growth that is not dependent on natural resources (Alnajar, 2019)

Research and development are a term that means scientific activities that are carried out, whether at the governmental or private sector level, for the purpose of discovering solutions to specific problems or creating new services or goods in many areas of interest. In other words, research and development is the basis for developed countries in general and industrial 
companies in particular towards the future, or more precisely, towards shaping the future that they want to achieve for the peoples (Alshaiba, 2016). The adoption of this strategy by the organizations works to increase the capabilities of strategic innovation of tourism companies by increasing their ability to research and development in a way that leads to the creation and development of products and services provided by them.

\subsection{Sustainability Business}

The primary concern for business sustainability or the sustainability of organizations is to ensure that the various institutions, whether governmental, non-governmental or the private sector, perform an effective and influential role in achieving sustainable development in general, without all these institutions combined, nothing can be done at all. Sustainability, in its simplified sense and as defined by Professor Knut Hannes; Professor of International Strategy and Management at IMD, is a business strategy; In order to provide long term value; By taking into account how a particular organization operates in the ecological, social and economic environment, sustainability is also based on the assumption that developing such strategies can extend the life of the company (Elwani, 2020). The importance of business, in its most general form, is demonstrated in that it is the only way for companies to survive, and to prolong the life of their limited and limited resources. In short, it is a strategy for the survival of everything on Earth and providing it with new opportunities. Therefore, it is not surprising that $62 \%$ of executives believe that a sustainability strategy is essential for companies to be competitive in today's world, while $22 \%$ say that it will be essential in the future (Almasri \& Abu-baker, 2018). If tourism companies do not have high-quality products, services and programs, customer participation will ultimately decline; So, it is important to get some things done very well, instead of doing a lot of things poorly, and the sustainable endeavors of a company are reflected in the programs they have and the products they offer.

\section{The Hypotheses to Be Tested}

\subsection{This first hypothesis}

$\mathrm{H}_{1}$ : There is no positive and significant relationship between strategic innovation and overall business sustainability in the Jordanian tourism sector."

Strategic Creativity and Sustainability Business is an interdependent relationship, as creativity is a strategy of sustainability and this is what has been confirmed by most studies. Whereas strategic innovation consists of sustainable technologies capable of making services or products that perform better than those already on the market (Perez et al., 2017). So, Hjalager (2018) has shown that strategic innovation is one of the important strategic management system dimensions in achieving a highly competitive advantage, and strategic innovation is distinguished from other strategic management dimensions that it includes a sustainable option.

Amer (2018) emphasized in an article published in a tourism newspaper in which he said, "For the successful institutions, in order to ensure their survival and continuity, are strong and influential, they must not be at the level of competence, meaning that they are convinced of doing their work in a correct way or perform their duties and their responsibility and their importance, in spite of their sincerity and faithfulness. Then throw her eyesight to the farthest and her hopes up to the highest, so that she is radiant in ideas, performance and goals".

\subsection{The second hypothesis}

\section{$\mathrm{H}_{2}$ : There is no positive significant impact of strategic innovation on overall business sustainability in the Jordanian tourism sector}

Strategic innovation has an impact on business sustainability, and this has been confirmed by several studies. Including the study of (Almasri \& Abu-baker, 2018), which proved that strategic planning in general has a positive impact on economic sustainability in terms of product development and value-added generation. This is what the current paper discusses, as it examines the development of services for the tourism sector and the generation of added value for its services in the Corona pandemic. This was also confirmed by the study of (Imare and Salah-Aldin, 2018), the results of which showed that the effectiveness of the innovation strategy has an impact on the sustainability of the business environment and that this effect fulfills the demands of sustainability for the business environment of the UNDP. Also, Study (Ezzi and Jarboui, 2016), the focus is on the specific problem of analyzing the impact of innovation strategy (particularly investment in research and development) on financial, social and environmental performance. These environmental, social and environmental factors are among the requirements of sustainability, the results are noteworthy and important to the extent that one can say that the innovation strategy has a crucial impact on the performance of the companies.

\section{Methodology}

This paper used the descriptive and analytical approach, in order to gain accurate knowledge of the elements of the problem, which searches for the role of strategic innovation in the sustainability of business in the Jordanian tourism sector during the Corona pandemic, since this paper studies this phenomenon in reality. 
The sample included 319 workers in tourism sector in Jordan from all the services provided. Fig. 1 summarizes the distribution of companies according to tourism services.

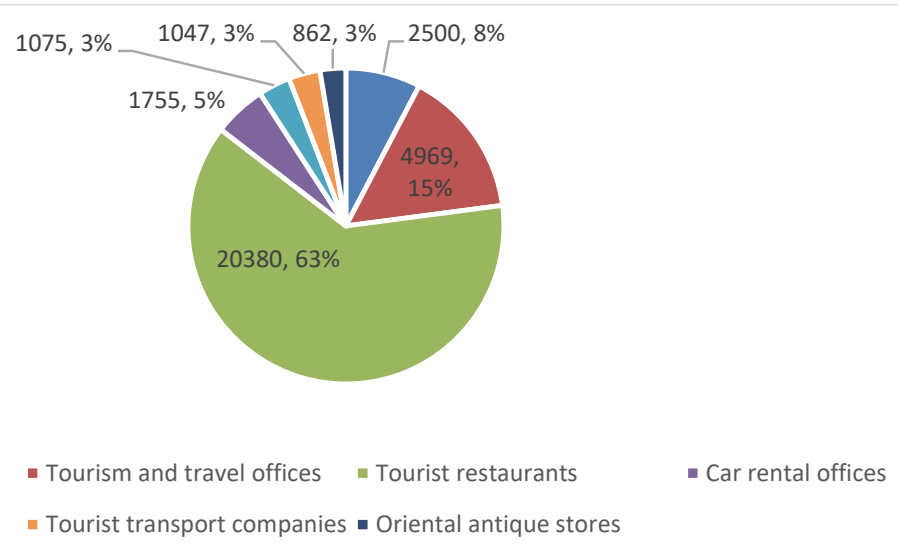

Fig. 1. The Number of Workers in Tourism Sector

Source: (Statistics and Ministry of Tourism, 2018).

The sample is chosen randomly, and Fig. 2 shows the distribution of the sample members according to demographic variables.

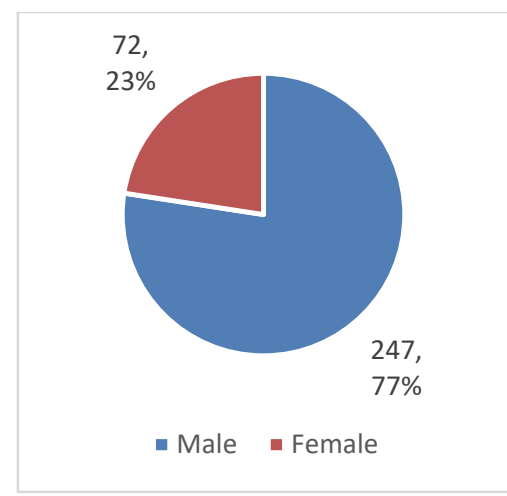

Gender

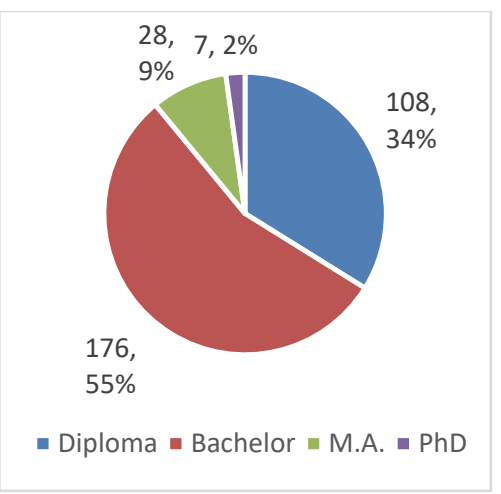

Educational background

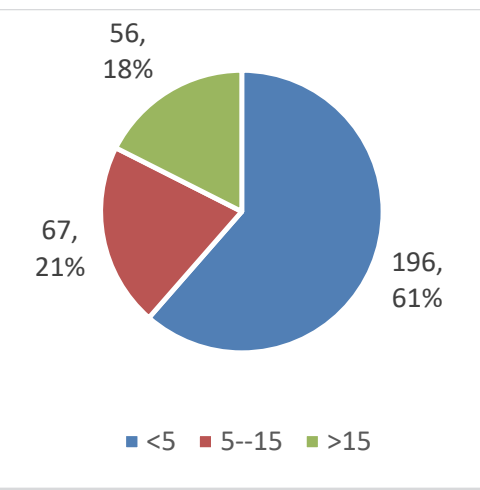

Years of Experience

Fig. 2. Distribution of the sample according to the variables of the study

Fig. 2 shows the following:

- Depending on the gender variable, males are the most frequent, which reached (247) percentage (77.4\%), while females are the least frequent, which reached (72) and with a percentage $(22.6 \%)$.

- Depending on Educational level variable, the employees who hold a bachelor's degree are the most frequent, which reached (176) a percentage (55.2\%), while employees with a $\mathrm{PhD}$ qualification are the least frequent, which reached (7) and a percentage $(2.2 \%)$.

- According to the variable Years of Experience, the employees who have service (5 years or less) are the most frequent, which reached (196) percentage $(61.4 \%)$, while the employees who have service (16-20 years) are the least frequent, which reached (56 And at a percentage $(17.6 \%)$.

\subsection{Collection and the data sources}

The purpose is to verify the role of innovation strategy in sustainability of business. So, to know about the data concerning the innovation strategy, and sustainability of business. Regarding innovation strategy, we gathered the needed data from the annual reports of the listed companies on the Jordanian Ministry of Tourism site, accessed the web-sites of the unlisted companies and contacted them by mail, fax and telephone to find out the necessary information to measure this variable. By using a questionnaire, we measured sustainability of business (the questionnaire is sent to the workers in the Tourism companies). The data collection was carried out in October /2020. We used several methods to gather information: personal investigation 
(by appointment: direct interview with the company leader of a duration of 45 minutes), telephone survey, fax inquiry and internet survey.

\subsection{Variables}

Variables in this context, is appropriate to separate the dependent variables from independent ones: the dependent variable is Sustainability Business is depending on the through consists of (6) paragraphs which are used by authors (Almasri and Abubaker, 2018; Silveira, 2013; Imare \& Salah-Aldin, 2018). And independent variable, it was measured by (Adopting an Innovation Creation Strategy; Adopting a Research and Development Strategy), these variables are depending on which are used by authors (Al-Aktash, 2019; Schroeder, 2013; Silveira, 2013; and Ezzi \& Jarboui, 2016).

\subsection{Questionnaire Validation}

The apparent validity was verified through the study tool (the questionnaire), by presenting it to a group of (15) specialized arbitrators from among the professors of the Commission's members. The teaching staff in Jordanian universities and specialists in business administration and strategic planning, and in light of their observations, the wording of the paragraphs was deleted and amended, and their opinions were taken into account. The questionnaire, in its semi-final form, in (22) statements, the dependent variable is Sustainability Business consists of (8) statements which are used by authors (Almasri \& Abu-baker, 2018; Silveira, 2013; Imare \& Salah-Aldin, 2018). And independent variable, it was measured by (Adopting an Innovation Creation Strategy; Adopting a Research and Development Strategy) are consists of (13) statements, which are used by authors (Al-Aktash, 2019; Schroeder, 2013; Silveira, 2013; Ezzi \& Jarboui, 2016).

Also, in order to ensure the stability of the study tool, the tool stability equation (Cronbach Alpha) was applied to all fields of study, and Table 1 illustrates this.

Table 1

Cronbach's alpha coefficients for the fields of study

\begin{tabular}{cccc}
\hline No. & The field & Number of paragraphs & Cronbach Alpha Coefficient \\
\hline 1 & Adopting an Innovation Creation Strategy & 7 & \\
2 & Adopting a Research and Development Strategy & 6 & 0.82 \\
3 & Sustainability Business & 9 & $\mathbf{2 2}$ \\
\hline
\end{tabular}

Table 1 shows that the Cronbach alpha coefficients for the study fields ranged between $(0.80-0.88)$, the highest was in the field of " Sustainability Business ", and the lowest was in the field of " Adopting a Research and Development Strategy ", and the Cronbach alpha coefficient for the questionnaire as a whole reached (0.94). And all the stability coefficients are high and acceptable for the purposes of the study, where the stability coefficient (Cronbach Alpha) is acceptable if it exceeds (0.60).

\section{Results}

This part includes a detailed presentation of the statistical analysis of the results of this paper. In order to achieve its objectives, these results will be presented based on the questions and hypotheses of this paper.

\subsection{Question 1}

So, the arithmetic mean and standard deviations of the questionnaire axes were calculated for (Adopting an Innovation Creation Strategy; Adopting a Research and Development Strategy and Sustainability Business) Table 2 illustrates this.

Table 2

The arithmetic means and standard deviations of the questionnaire axes

\begin{tabular}{|c|c|c|c|c|c|}
\hline No. & Statement & $\begin{array}{c}\text { Arithmetic } \\
\text { Average }\end{array}$ & $\begin{array}{l}\text { Standard } \\
\text { Deviation }\end{array}$ & Rank & Grade \\
\hline 1 & Adopting an Innovation Creation Strategy & 3.85 & .67 & 1 & High \\
\hline 2 & Adopting a Research and Development Strategy & 3.65 & .79 & 3 & Moderate \\
\hline 3 & Sustainability Business & 3.66 & .68 & 2 & Moderate \\
\hline & The Whole of Questionnaire & 3.72 & .65 & \multicolumn{2}{|c|}{ High } \\
\hline
\end{tabular}

Table 2 shows the arithmetic averages and standard deviations of the axes of the questionnaire, as the arithmetic mean of the questionnaire as a whole reached (3.72) and a standard deviation (0.65) at a high level, as the arithmetic averages ranged between (3.65-3.85), where the domain of adopting innovation creation strategy came first. With an arithmetic average (3.85) and a high level, and in the second place is the field of sustainability with an arithmetic average (3.66) and a medium level, and in the third and last place for adopting the research and development strategy with an arithmetic average (3.65) and a medium level. 
To answer this question, the researcher tested the hypothesis of the first study, which states: "There is no positive and significant relationship between strategic innovation and overall business sustainability in the Jordanian tourism sector", by using the Pearson correlation coefficient between the variables, and Table 3 shows that.

Table 3

$\underline{\text { Pearson correlation coefficient between strategic innovation and sustainability Business }}$

\begin{tabular}{ccc} 
Sustainability & Statistician & Strategic Innovation \\
\cline { 2 - 3 } Business. & Correlation Coefficient & $.870^{* *}$ \\
& Statistical Significance & .000 \\
\hline
\end{tabular}

Table 3 shows the Pearson correlation coefficient between strategic innovation and sustainability, as the results showed the existence of a strong and positive relationship with statistical significance between strategic innovation and sustainability business, as the value of the correlation coefficient was $(0.870)$ and in statistical terms $(0.00)$.

\subsection{Question 3}

To answer this question, the researcher tested the hypothesis of the second study, which states: "There is no positive significant impact of strategic innovation on overall business sustainability in the Jordanian tourism sector," by using multiple regression analysis of the dimensions of strategic innovation and its impact on sustainability in the Jordanian tourism sector Table 4 shows that.

Table 4

Multiple Regression Analysis to find out the impact of strategic innovation on business sustainability in the Jordanian tourism sector

\begin{tabular}{|c|c|c|c|c|c|c|c|c|}
\hline Independent Variable & $\boldsymbol{\beta}$ & $\mathbf{T}$ & Sig.*t & $\mathbf{R}$ & $\mathbf{R}^{2}$ & $\mathbf{F}$ & F Sig* & $\begin{array}{c}\text { Fixed } \\
\text { limit }\end{array}$ \\
\hline $\begin{array}{c}\text { Adopting an Innovation } \\
\text { Creation Strategy }\end{array}$ & .630 & 18.13 & .000 & \multirow{2}{*}{.884} & \multirow{2}{*}{.781} & \multirow{2}{*}{564.97} & \multirow{2}{*}{.000} & \multirow{2}{*}{.129} \\
\hline $\begin{array}{l}\text { Adopting a Research and } \\
\text { Development Strategy }\end{array}$ & .332 & 9.55 & .000 & & & & & \\
\hline
\end{tabular}

Table 4 shows the impact of strategic innovation on business sustainability in the Jordanian tourism sector. The results of the statistical analysis showed that there is a statistically significant effect of strategic innovation on business sustainability in the Jordanian tourism sector, as the correlation coefficient $\mathrm{R}$ reached $(0.884)$ at a significant level $(\alpha \leq 0.05)$. As for the determination coefficient R2, it reached (0.781), meaning that strategic innovation explains $78.1 \%$ of the changes in business sustainability in the Jordanian tourism sector. Confirms the correctness of rejecting the hypothesis, which states: "There is no significant impact of strategic innovation on business sustainability in the Jordanian tourism sector at the significance level (0.05)," as the results showed the following:

1- There is a statistically significant impact of adopting the innovation creation strategy on business sustainability in the Jordanian tourism sector, where the value of T reached (18.13) and in statistical terms $(0.00)$, which is a function of the level of significance $(\alpha \leq 0.05)$, and the value of the degree of impact $(0.630)$ This means that a one-degree increase in the adoption of the innovation creation strategy leads to an increase in the level of business sustainability in the Jordanian tourism sector by a value of $(0.630)$.

2- There is a statistically significant effect of adopting a research and development strategy on business sustainability in the Jordanian tourism sector, where the value of T reached (9.55) and in statistical terms $(0.00)$, which is a function of the level of significance $(\alpha \leq 0.05)$, and the value of the degree of impact $\beta(0.332)$ This means that a one-degree increase in the adoption of the research and development strategy leads to an increase in the level of business sustainability in the Jordanian tourism sector by a value of $(0.332)$.

\section{Discussion}

The results of the study showed that the sample from which the data were collected is that the majority of those working in the Jordanian tourism sector are males, which reached (77\%), which is the largest percentage. This indicates the absence of a feminine character in the tourism sector, which caused the loss of a kind of psychological balance that was subjected to a kind of pressure due to the Corona pandemic. In addition, most of these males hold an academic qualification with only a bachelor's degree (55\%), and the rest for a diploma, and this indicates the weak educational level of the Jordanian tourism sector cadres. As higher education supports the phenomenon of research and development and solving sudden problems such as the Corona pandemic. As for work experience in the tourism sector, it is little, because the majority of the sample (61\%) confirmed that 
their experiences do not exceed 5 years, and this indicates that the lack of experience made the Jordanian tourism sector to stand baffled in front of the Corona pandemic.

As for the study questions. The results indicated the following:

The first question: The results showed that the level of implementation of strategic innovation through Adopting an Innovation Creation Strategy is a high This indicates that the Jordanian tourism sector has innovative strategies, because the company's employees have the competence to think independently regarding tourism services. The company simulates systems for analyzing and adjusting services to adapt to the desires and behavior of tourists. The company provides systems with innovative efficiencies essential to the tourism service life cycle. The company is proficient in creative thinking. The company provides its services to tourists on time and with high quality. The company carries out innovation activities in tourism services. The company defines the business problem and constraints (time, resources, market).

But the level of implementation of strategic innovation through Adopting a Research and Development Strategy is a Moderate, this indicates that the Jordanian tourism sector has innovative strategies, because the company does not work to develop the information network for tourists, nor does it have an interest in data collection, experimentation and negotiation. In addition, the company does not develop social relationships with unfamiliar actors inside or outside Jordan, even after the Covid19 pandemic. The company is not collecting and reviewing alternative strategies during the Covid-19 pandemic. Weakness The company is cooperating with universities and research institutes to develop new ideas to avert the Covid-19 pandemic. The company is constantly developing the technology for serving the tourists. In addition to the fact that the majority of workers in the tourism sector are males with the highest educational attributes of a bachelor's degree and a diploma, the absence of those with higher studies loses the strategy of research and development, and this also indicates the absence of the Jordan Tourism Authority from the real problem.

As for the level of business sustainability, it is high, because the company builds trust, a common vision and agreement on basic values in the tourism sector. The company is constantly processing electronic data on the tourism sector after the Covid19 pandemic. The company deals with the tourism service requirements constantly. The company has the potential to integrate business, environmental, informational and social problems. The company integrates the perspectives and knowledge of different actors in the tourism sector. In addition, the company integrates traditional standards of efficiency with environmental and social efficiency and effectiveness. The company applies knowledge gained in previous projects to new projects related to the tourism sector. The company is integrating differences in information processing and decision patterns that pertain to tourism services, especially during the Covid-19 pandemic. The company also addresses the differences in the focus and degree required to maximize the outcome in the tourism service. This indicates that the tourism sector is able to rise again after the end of the Corona pandemic, because it has sustainability in its business, and this crisis will only be temporary.

The second question: The relationship between strategic innovation and its variables and business sustainability is a strong relationship, meaning that strategic innovation supports and maintains business sustainability in the Jordanian tourism sector. In addition, this relationship is positive oriented, as the more interest and support for strategic innovation in the tourism sector, the more the sector will ensure the continuity of its business even after the economic collapse caused by the Corona pandemic.

On the other hand, this proves the opposite of the hypothesis imposed by the study that there is no relationship between its variables and that it confirms the rejection of the null hypothesis and acceptance of the alternative hypothesis, which states "There is a positive and significant relationship between strategic innovation and overall business sustainability in the Jordanian tourism sector.".

The third question: The results of the analysis showed a statistically significant effect of strategic creativity through its variables (Adopting an Innovation Creation Strategy and Adopting a Research and Development Strategy) on business sustainability in the Jordanian tourism sector, and this effect means that a one-degree increase in the Adopting an Innovation Creation Strategy or Adopting a Research and Development Strategy leads to an increase in the level of sustainability in the Jordanian tourism sector.

On the other hand, this proves the opposite of the hypothesis imposed by the study that there is no relationship between its variables and that it confirms the rejection of the null hypothesis and acceptance of the alternative hypothesis, which "There is no positive significant impact of strategic innovation on overall business sustainability in the Jordanian tourism sector".

\section{Conclusion}

We know that the strategic performance of the Jordanian tourism sector before the Corona pandemic covered the local income of the state by $11 \%$, and employed a large proportion of employment until the Corona pandemic came and the tourist bottom was affected, as is the case with other sectors. Therefore, this study came to search for a strategy to restore the vitality of this sector, which is the role of strategic innovation with its variables on business sustainability. Several questions were asked in order to know the level of implementation of strategic innovation in the Jordanian tourism sector, and whether the nature of this business is a template for renewal again. This is what the current study has proven that there is a high level in that. In addition, she explained that strategic innovation has a positive impact on business sustainability in the Jordanian tourism sector. The study recommends that the Jordanian tourism sector should adopt a strategy of research and development and pay 
attention to the educational level of employees better in order to overcome the Corona pandemic and make up for what was lost during the pandemic.

\section{References}

Al-Aktash, N.M. (2019). The Impact of Electronic Leadership Practices on Strategic Innovation: Testing the Mediating Role of the Internet of things, Master's thesis, Department of Business Administration, Middle East University, Jordan.

Al-Khudairi, Y. (2020), Corona crisis and tourism, Published article, official Jordanian newspaper from Al-Ghad newspaper official website: https://alghad.com/.

Almasri, S. H., \& Abu-baker, S. (2018), The Impact of Strategic Planning for Human Resources on Business Sustainability for Jordanian Technology and Information Companies. Jordan Journal of Applied Globalism, Humanities Series, 20(1).

Alnajar, E. (2019). Research and development. your way towards innovation, electronic magazine, entrepreneurs, the official website: https://www.rowadalaamal.com/.

Alshaiba, A., M. (2016), Research and development ... a strategic necessity, an electronic magazine, its website: https://www.alittihad.ae/wejhatarticle/89120/.

Amer, A. (2018), The Impact of Creativity, Innovation and Unconventional Thinking on Economic Growth, Sphinx Tourism Newspaper. From the official website: http://www.abou-alhool.com/arabic1/details.php?id=40171\#.X8UV-s0zbIU.

Elwani, M., (2020), Institutional sustainability ... its importance and dimensions, electronic magazine, entrepreneurs, the official website: https://www.rowadalaamal.com/.

Ezzi, F., \& Jarboui, A. (2016). Does innovation strategy affect financial, social and environmental performance? Journal of Economics. Finance and Administrative Science, 21(40), 14-24.

Imare, A., A., \& Salah-Aldin, A. D. (2018), Green innovation is an effective strategy for facing the challenges of achieving environmental sustainability for business organizations. Journal of Economic and Management Sciences, 19(1) 2018, ISSN (Print):1858-6740 e-ISSN (Online):1858-8573.

Kalay, F., \& Gary, L. Y. N. N. (2015). The impact of strategic innovation management practices on firm innovation performance. Research Journal of Business and Management, 2(3), 412-429.

Kim, S. (2014). Local electronic government leadership and innovation: South Korean experience. Asia Pacific Journal of Public Administration, 30(2), 165-192.

Purba, J. T. (2015). Strategic Innovation through Technology Readiness and Acceptance in Implementing ICT for Corporate Sustainability. Proceedings. Presented in 12th International annual symphosium on management, in Makassar March.

Schroeder, H. (2013). Strategic innovation for business performance: The art and science of transformation. Technology Innovation Management Review, 3(9).

Silveira, M. A. (2013). Strategic management of innovation towards sustainable development of Brazilian electronics industry. Journal of technology management \& innovation, 8, 45-45.

Zarrabi, F., Poursadegh, N., \& Jafarvand, S. (2013). Alignment between innovation strategy and outcomes. Procedia-Social and Behavioral Sciences, 75, 18-24.

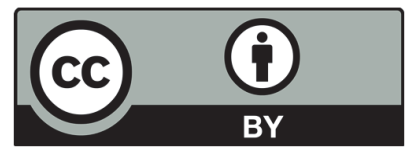

(C) 2021 by the authors; licensee Growing Science, Canada. This is an open access article distributed under the terms and conditions of the Creative Commons Attribution (CC-BY) license (http://creativecommons.org/licenses/by/4.0/). 